\title{
Effect of Irgacure 651 Initiator on Poly(Methyl Methacrylate) Photostability Studied by UV-Vis Spectroscopy ${ }^{\#}$
}

\author{
Halina Kaczmarek* and Piotr Gałka
}

\author{
Faculty of Chemistry, Nicolaus Copernicus University, 7, Gagarin Str., 87-100 Toruń, Poland
}

\begin{abstract}
Commercial initiator - 2,2-dimethoxy-2-phenyl acetophenone (Irgacure 651, Ciba, Switzerland) was introduced to poly(methyl methacrylate) (PMMA) matrix to enhance the polymer degradation. Two types of thin polymeric films (PMMA and PMMA+5\% Irgacure) were UV-irradiated in laboratory conditions (Xenon lamp, air atmosphere, room temperature). The photochemical changes in pure PMMA and PMMA doped with the initiator were studied by absorption spectroscopy in the UV-Vis range. Separately, the behaviour of the initiator in the acetonitrile (ACN) solution upon UVradiation was investigated at the same conditions. It was found that the addition of the Irgacure 651 to PMMA accelerated the photooxidative degradation, particularly at the early stages of exposure. The efficiency of formation of chromophoric groups in PMMA in the presence of the Irgacure initiator was significantly greater than in pure polymer. This suggests that the free-radical products of the initiator photolysis (mainly benzoyl radicals) are able to abstract hydrogen atoms from PMMA molecules.
\end{abstract}

\section{INTRODUCTION}

Irgacure photoinitiators constitute a family of commercial compounds, produced by Ciba Specialty Chemicals, Switzerland. They are well known as efficient intiators of polymerization of various kinds of monomers [1-7]. Such initiators as benzyl ketals, $\alpha, \alpha$-dialkoxyacetophenones and $\alpha$-hydroxyalkylphenones contain chromophoric groups that absorb radiation in ultraviolet or visible range and undergo photolysis with formation of free radicals. The photochemical properties and photoinitiation activity of these organic compounds in polymerization and crosslinking of acrylated monomers were studied by various experimental methods. One of the most efficient photoinitiators in this group is Irgacure 651 (DMPA), $\mathrm{C}_{6} \mathrm{H}_{5}-\mathrm{CO}-\mathrm{C}\left(\mathrm{OCH}_{3}\right)_{2}-\mathrm{C}_{6} \mathrm{H}_{5}[1,2]$. The compound is characterized by high phosphorescence quatum yield $(\Phi=0.62)$ and relatively long triplet lifetime $\left(\tau_{1 / 2}=\right.$ $2.59 \mathrm{~ms})$. High polymerization rate and large conversion degree in the presence of DMPA is explained by the significant benzoyl radical concentration, which was confirmed by flash photolysis. The initial concentration of the initiator in photopolymerised formulation has a great influence on the molecular weight and polydispersity of the obtained polymer [8].

Although the photoinitiating action of Irgacure compounds is well documented, the idea of using of these photoinitiators as degrading agents for the purpose of obtaining of the degradable materials is rather new. Our preliminary work, considering this topic, gives the promising information useful for designing the polymeric materials with controlled life-time.

\footnotetext{
*Address correspondence to this author at the Faculty of Chemistry, Nicolaus Copernicus University, 7, Gagarin Str., 87-100 Toruń, Poland; E-mail: halina@chem.uni.torun.pl

"Presented on the $42^{\text {nd }}$ IUPAC World Polymer Congress, Polymers at Frontiers of Science and Technology, Taiwan, Taipei, 2008.
}

The aim of this presentation is to study the photostability of poly(methyl methacrylate) (PMMA) doped with 2,2dimethoxy-2-phenyl acetophenone initiator (abbreviation DMPA, trade name - ${ }^{\circledR}$ IRGACURE 651) and to compare the course of photochemical reaction in doped and undoped polymers using UV-Vis spectroscopy.

\section{MATERIALS AND METHODOLOGY}

The poly(methyl methacrylate) $\left(\mathrm{M}_{\mathrm{w}}=120000\right.$, SigmaAldrich) was used without purification. The photointiator ${ }^{\circledR}$ Irgacure 651 was supplied by Ciba, Basel, Switzerland. The polymer and the initiator were dissolved in tetrahydrofurane. Thin polymeric films were obtained by casting the solution directly onto spectroscopic windows. The modified PMMA contained 5\%(wt) of Irgacure 651.

The polymeric samples were UV-irradiated at room temperature and in air for 1-24h using high pressure xenon lamp XBO R $180 \mathrm{~W} / 45$ OFR with ZXE 180 power supply adaptor (provided by Optel, Opole, Poland). The intensity of incident light, monitored by the HD 9021 radiometer (Delta, Italy), was equal to $35.2 \mathrm{~W} / \mathrm{cm}^{2}$ (for UV-A), $9.70 \mathrm{~W} / \mathrm{cm}^{2}$ (UV-B) and $2.30 \mathrm{~W} / \mathrm{cm}^{2}$ (UV-C).

The UV-Vis spectra of the pure PMMA and the polymer doped with DMPA were recorded by UV-1601PC spectrometer (Shimadzu, Japan).

DMPA initiator was exposed to the radiation emitted from Xenon lamp in acetonitrile (ACN) solutions at different concentrations. The irradiation and spectroscopic studies were performed using a quartz cell with a path length of 1 $\mathrm{cm}$.

\section{RESULTS AND DISCUSSIONS}

The changes of electronic spectra of Irgacure 651 in ACN solutions caused by the UV-irradiation are shown in 
Fig. (1). The main bands with the maxima at 205, 251 and $341 \mathrm{~nm}$ are present, which is in a good agreement with the literature data [2]. These bands are attributed to $\pi \rightarrow \pi^{*}$ and $\mathrm{n} \rightarrow \pi^{*}$ transitions.

The Fig. (1A) shows the decrease of the band intensity at 205 and $251 \mathrm{~nm}$ with the simultaneous formation of a new absorption peak at $223 \mathrm{~nm}$ during the 20 minutes of exposure. The low-intensity band at higher wavelenght (341 nm) also disapears rapidly, which is clearly observed in spectrum recorded for more concentrated solution (Fig. 1B). It indicates that Irgacure 651 undergoes the efficient photolysis in applied conditions.

A

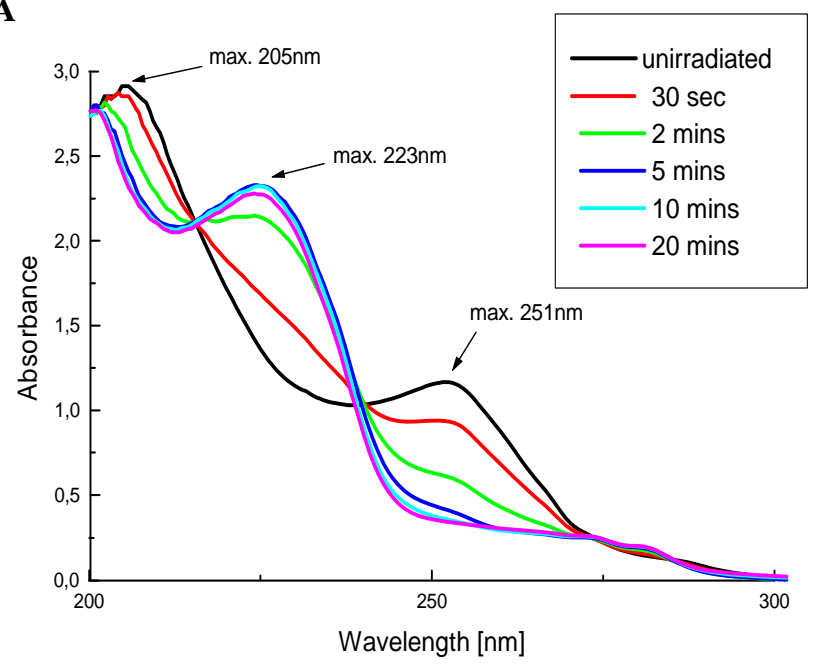

B

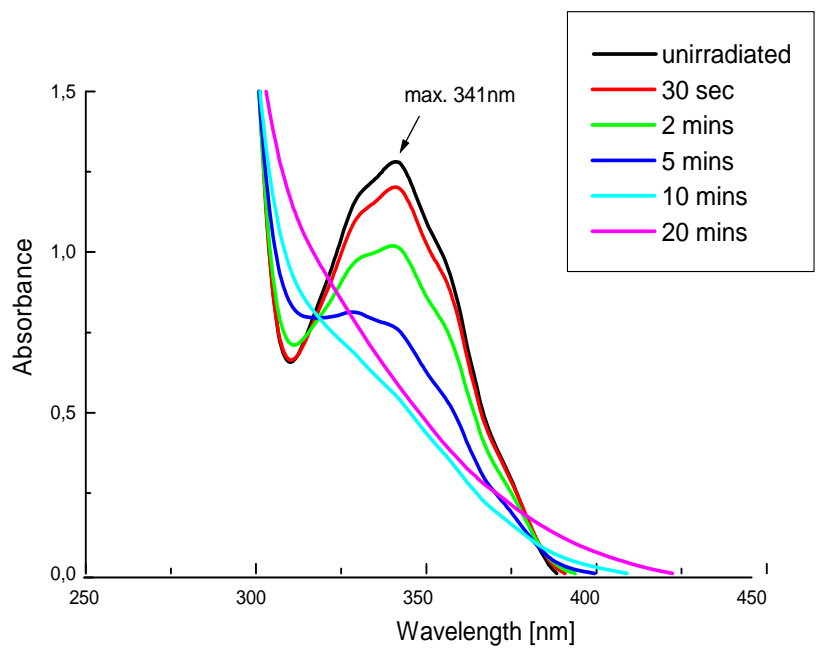

Fig. (1). The changes in UV-Vis absorption spectra of Irgacure 651 in ACN solutions during UV-irradiation: $(A) C_{\mathrm{m}}=8.8 \times 10^{-5} \mathrm{~mol} / \mathrm{dm}^{3}$; (B) $\mathrm{C}_{\mathrm{m}}=4.4 \times 10^{-3} \mathrm{~mol} / \mathrm{dm}^{3}$.

The carbonyl organic compounds of benzoin type, after the photon absorption and excitation undergo the $\alpha$ dissociation (Norrish type I cleavage) according to Scheme 1. This reaction is very fast and formed benzoyl (1) and $\alpha, \alpha$ dimethoxybenzyl radicals (2) differ significantly in their reactivity [9-13]. The fragmentation of the latter one leads to the formation of small methyl radical (3) and methyl benzoate (4). Both (1) and (3) radicals participate in photoinitiated polymerization but the action of ${ }^{\bullet} \mathrm{CH}_{3}$ is much less effective than this of (1). Moreover, other major products of DMPA photolysis are benzaldehyde, benzil and acetophenone [14]. Benzil, which is diketone $\left(\mathrm{C}_{6} \mathrm{H}_{5} \mathrm{C}=\mathrm{O}\right)_{2}$ is also used as a photoinitiator in the polymer curing.

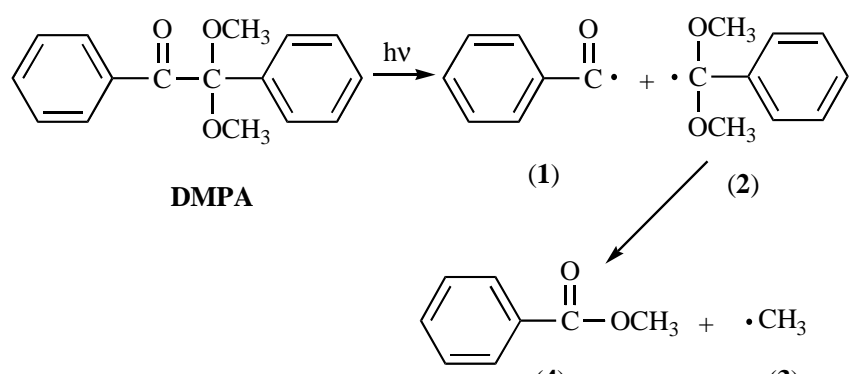

(4)

(3)

Scheme 1. Photolysis of Irgacure 651 initiator.

The photostability of PMMA and PMMA + Irgacure 651 films of the same thickness were investigated using UV-Vis spectroscopy. The examples of changes in UV-Vis spectra of these samples are presented in Fig. (2). As can be noticed, the band at $251 \mathrm{~nm}$, atributed to the photoinitiator, is present in the spectrum of the modified PMMA. However, it disapears already in the first hour of UV-irradiation.

The other signals due to initiator are difficult to detect in PMMA spectrum. The maximum at $205 \mathrm{~nm}$ overlaps the carbonyl band from PMMA; the band at $341 \mathrm{~nm}$, owing to its low absorption coefficient [8] and because of low DMPA concentration in polymeric sample is hardly seen.

The prolongation of exposure time causes an increase of the absorbance in the $200-400 \mathrm{~nm}$ range. The observed changes in UV-Vis spectra of both polymeric samples are irregular - particularly fast increase of the absorbance was observed at the beginning of the irradiation. The broad absorption band formed during the sample exposure indicates that the complex mixture of photoproducts arises. The increase of the absorbance in both UV-irradiated samples can be explained by the formation of the new functional groups such as carbonyls in main chain and separated or conjugated double bonds. It is known that PMMA undergoes mainly depolymerisation but furthermore a random chain scission takes place [15]. The created monomer and oligomers containing unsaturated bonds accumulated in the matrix additionally increase the absorption of the degraded polymer.

The solvent impurities which are present in both unexposed samples have no significant effect on the photodegradation rate, what was proved in the previous experiment.

However, to investigate the kinetics of chromphore formation more thoroughly and to avoid the possible errors, the absorbance at $300 \mathrm{~nm}$ (which is outside of initiator absorption) was chosen for comparison the behavior of the PMMA and PMMA + DMPA samples.

Fig. (3) shows the differences in the kinetics of the photochemical reaction leading to the generation of the products absorbing at $300 \mathrm{~nm}$. The rapid absorbance increase after $1 \mathrm{~h}$ irradiation is an evidence of the fast reaction in the first pe- 
riod of the experiment. The next stage of photooxidative degradation is significantly restrained. The yield of the chromophoric group formation in the modified PMMA is a few times higher that in pure polymer. It is obviously caused by high concentration of the free radicals formed as a result of the DMPA decay.

The enhancement of the photoreaction in the modified PMMA can be explained by the reaction of the initiating species from DMPA with macromolecules. Most probable is the hydrogen abstraction from PMMA (Scheme 2).

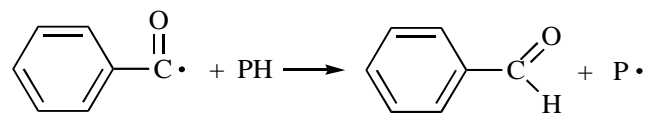

Scheme 2. Initiation of PMMA decomposition by benzoyl radical.

The macroradical $\left(\mathrm{P}^{*}\right)$ undergoes the secondary reactions, for example the addition of the oxygen molecules with the formation of peroxyradicals $\left(\mathrm{POO}^{\circ}\right)$, which is a typical process for many polymers [15].

A

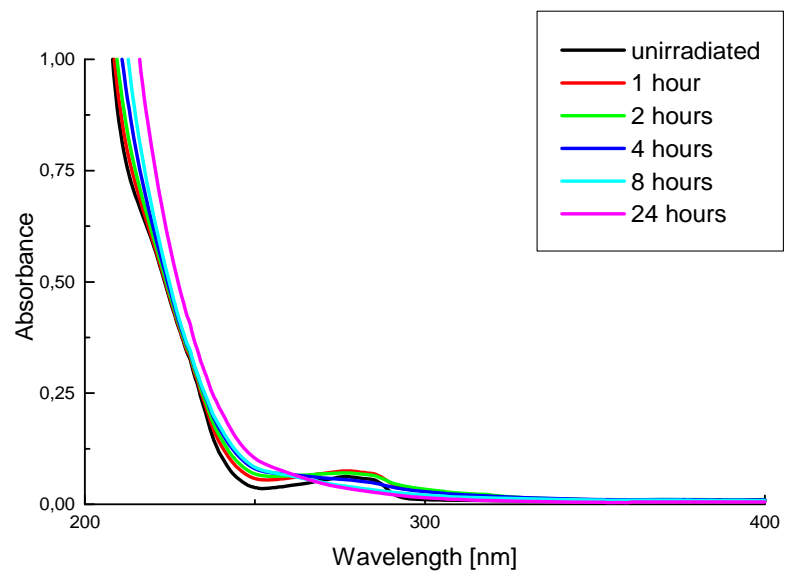

B

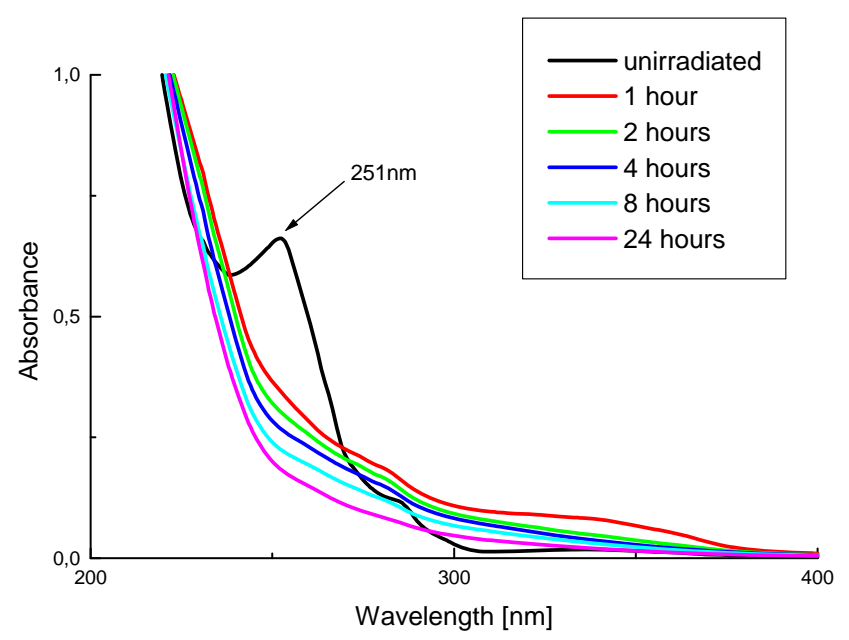

Fig. (2). Changes of UV-Vis spectra of the pure PMMA (A) and PMMA doped with Irgacure 651 (B) during the exposure to Xenon lamp.

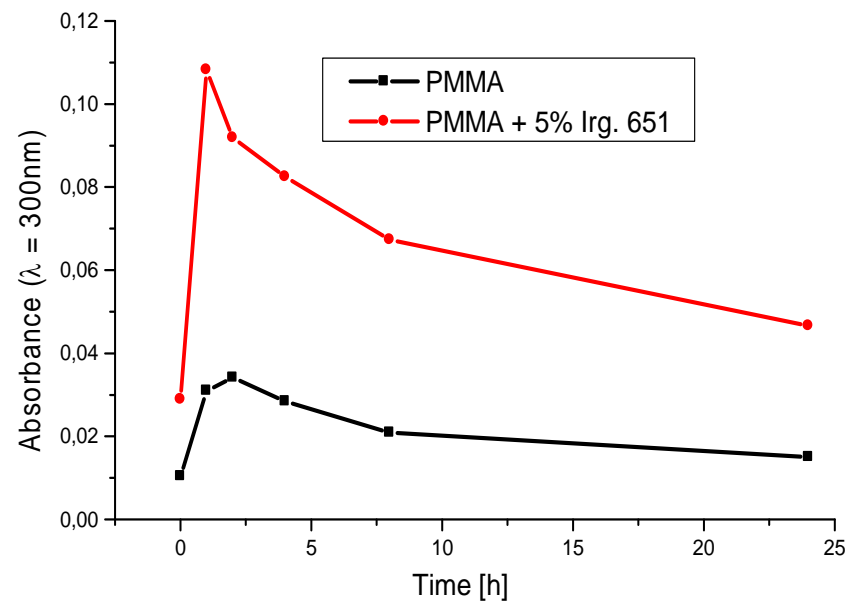

Fig. (3). The kinetics of chromophore formation in the pure PMMA and the PMMA containing 5\% Irgacure 65 during the exposure to Xenon lamp.

\section{CONCLUSIONS}

It was found that the presence of smal amount of 2,2dimethoxy-2-phenyl acetophenone in PMMA film accelerates its photodegradation.

Photolysis of DMPA in PMMA matrix is slower than in acetonitrile solution. This is caused by trapping of the initiator in the stiff polymer matrix where the mobility of the molecules is restricted, contrary to the solution. However, the concentration of the free radicals formed during the DMPA photodecomposition is high enough for the initiation of the macromolecules scission. The photooxidative degradation, leading to the chromophore formation, occurs in the doped PMMA with the higher rate and efficiency comparing to the virgin PMMA.

\section{ACKNOWLEDGEMENTS}

The financial support from a Rector grant (Nicolaus Copernicus University, Torun, Poland, grant number: 561-Ch) is gratefully acknowledged.

\section{REFERENCES}

[1] Segurola, J.; Allen, N.; Edge, M.; McMahon, A.; Wilson, S. Photoyellowing and discolouration of UV cured acrylated clear coatings systems: influence of photoinitiator type. Polym. Degrad. Stab., 1999, 64, 39-48

[2] Segurola, J.; Allen, N.; Edge, M.; Roberts, J. Photochemistry and photoinduced chemical crosslinking activity of acrylated prepolymers by several commercial type I far UV photoinitiators. Polym. Degrad. Stab., 1999, 65, 153-160.

[3] Allen, N.S.; Marin, N.C.; Edge, M.; Davies, D.W.; Garret, J.; Jones, F.; Navaratnam, S.; Parsons, B.J. Photochemistry and photoinduced chemical crosslinking activity of type I \& II co-reactive photoinitiators in acrylated prepolymers. J. Photochem. Photobiol. A: Chem., 1999, 126, 135-149.

[4] Berner-Kowollik, C.; Vana, P.; Davis, T.P. Laser-induced decomposition of 2,2-dimethoxy-2- phenylacetophenone and benzoin in methyl methacrylate homopolymerization studied via matrixassisted laser desorption/ionization time-of-flight mass spectrometry. J. Polym. Sci., Part A. Polym. Chem., 2002, 40, 675-681.

[5] Studer, K.; Decker, C.; Beck, E.; Schwalm, R. Overcoming oxygen inhibition in UV-curing of acrylate coatings by carbon dioxide inerting: Part II. Prog. Org. Coat., 2003, 48, 101-111. 
[6] Masson, F.; Decker, C.; Andre, S.; Andrieu, X. UV-curable formulations for UV-transparent optical fiber coatings I. Acrylic resins. Prog. Org. Coat., 2004, 49, 1-12.

[7] Schafer, K.J.; Hales, J.M.; Balu, M.; Belfield, K.D.; Van Stryland, E.W.; Hagan, D.J. Two-photon absorption cross-sections of common photoinitiators. J. Photochem. Photobiol. A: Chem., 2004, $162,497-502$

[8] Teixeira, S.; Giudici, R.; Bossmann, S.H.; Lang, J.; Braun, A.M. Approaches towards a technically feasible photoinitiated prepolimeryzation of methyl mathacrylate. Chem. Eng. Proc., 2004, 43, 1317-1328.

[9] Scherzer, T.; Decker, C. Real-time FTIR-ATR spectroscopy to study the kinetics of ultrafast photopolymerization reactions induced by monochromatic UV light. Vib. Spectrosc., 1999, 19, 385398.

[10] Lipscomb, N.T.; Tarshiani, Y. Kinetics and mechanism of the benzoin isobutyl ether photoinitiated polymerization of styrene. $J$. Polym. Sci., Polym. Chem. Ed., 1988, 26, 529-540.
[11] Fouassier, J.P.; Rabek, J.F., Eds. Radiation Curing in Polymer Science and Technology - Vol. II. Photoinitiating systems, Elsevier Applied Science, London, 1993.

[12] Linden, L-A.; Pączkowski, J.; Rabek, J.F.; Wrzyszczyński, A.

Fotoinicjatory polimeryzacji rodnikowej: fotodysocjujące $\mathrm{i}$ z przeniesieniem elektronu. Polimery, 1999, 44, 161-176.

[13] Wrzyszczyński, A. Organiczne zwiazki siarki jako inicjatory koinicjatory fotopolimeryzacji rodnikowej, Rozprawy $\mathrm{Nr} 112$, ATR, Bydgoszcz, 2004.

[14] Groenenboom, C.J.; Hageman, H.J.; Overeem, T.; Weber, A.J.M. Comparison of the photodecompositions of $\alpha$-methoxy- and $\alpha, \alpha$ dimethoxydeoxybenzoin in 1,1_diphenylethylene as model substrate. Makromol. Chem., 1982, 183, 281-292.

[15] Rabek, JF. Polymer photodegradation: mechanisms and experimental methods, Chapman \& Hall, London, 1995.

(c) Kaczmarek and Gałka; Licensee Bentham Open.

This is an open access article licensed under the terms of the Creative Commons Attribution Non-Commercial License (http://creativecommons.org/licenses/ by-nc/3.0/) which permits unrestricted, non-commercial use, distribution and reproduction in any medium, provided the work is properly cited. 